\title{
OBITUARIO
}

\section{CARLOS ALBERTO NARANJO}

(1941-2005)

El 28 de enero falleció en la ciudad Autónoma de Buenos Aires el Dr. Carlos Alberto Naranjo. Había nacido en Buenos Aires el 20 de junio de 1941.

Obtuvo su título de Doctor en Ciencias Biológicas en la Facultad de Ciencias Exactas y Naturales de la Universidad de Buenos Aires y en ella ejerció los cargos desde Ayudante de Segunda hasta Profesor Asociado. Desde 1993 fue Profesor Titular de Genética y mejoramiento Vegetal en la Facultad de Ciencias Agrarias y Forestales de la Universidad Nacional de La Plata.

Destacado investigador, fue miembro activo de varias Sociedades Científicas y Presidente de la Sociedad Argentina de Botánica y de la Sociedad Argentina de Genética. Publicó unos sesenta y siete trabajos en revistas nacionales e internacionales y cincuenta comunicaciones cortas en revistas especializadas extranjeras. También ciento treinta y siete trabajos en reuniones científicas.

Desde el $1^{\circ}$ de noviembre de 1987, hasta su deceso, fue Director del Instituto Fitotécnico de Santa Catalina de la Facultad de Ciencias Agrarias y Forestales de la Universidad Nacional de La Plata, cargo obtenido por concurso y con la jerarquía de Profesor Titular con dedicación exclusiva.

El Dr. Carlos Alberto Naranjo tuvo durante su vida una intensiva y muy amplia participación en la formación de recursos humanos: una especial dedicación en la formación de becarios y tesis de maestría y doctorado. Hombre apasionado por su trabajo y siempre bien dispuesto, brindó sus ideas a quienes las necesitaren: novedades tecnológicas en el campo de la citogenética, asesoramiento inteligente y crítico, etc. Me distinguió brindándome sus conocimientos y su tiempo en su laboratorio y en reuniones científicas en las que coincidimos. También me abrió las puertas de su casa y en esas estadías disfruté de su compañía y de la cálida gentileza de su esposa Lidia. Momentos inolvidables por la riqueza afectiva y laboral que significaron.

Su pérdida enluta a su familia y a toda la familia universitaria argentina.

Aveliano Fernández 